$\begin{gathered}\text { EPiC Series in Built Environment } \\ \text { Volume 2, 2021, Pages 284-292 } \\ \text { ASC 2021. 57th Annual Associated Schools } \\ \text { of Construction International Conference }\end{gathered}$
Built
Environment

\title{
Exploring Construction Students' Perceptions of Smart Buildings
}

\author{
Saeed Rokooei, Ph.D. \\ Mississippi State University \\ Starkville, MS
}

\author{
Ali Karji \\ Pennsylvania State University \\ State College, PA
}

\begin{abstract}
Smart buildings use technologies to interconnect different building systems' data for performance improvement. These buildings can improve the user experience, decrease operation and maintenance costs, and elevate productivity, to name a few. With the advent of information technology, the market for smart building technology is increasingly expanding. Smart buildings and relevant synonyms are becoming prevalent in the architecture, engineering, and construction industries (AEC); however, it is not widely taught in construction education programs. This study aims to determine the current understanding and perception levels of construction management students of the aspects of smart buildings. To do this, two groups of construction management students from Japan and the U.S. were surveyed before and after a smart building workshop. A quantitative research method was used to collect and analyze the data. The results showed similarities and differences between the two groups' attitudes toward different aspects of smart buildings, the workshop's role in changing students' perceptions of smart buildings, and construction education institutions' role in promoting the smart building concept. This study helps education programs by shedding light on the current knowledge of a sample of students about smart buildings and highlights aspects of the concept that need a focus in educational settings.
\end{abstract}

Key Words: Smart Building, Construction Education, Project-Based Learning, Japan, USA, Perception

\section{Introduction}

The notion of smart buildings is increasingly attracting the attention of construction professionals and educators. In recent years, technological advancements have provided designers and builders with a diverse toolkit to make a "smarter" built environment. Tools, methods, and systems used in the smart building paradigm are haphazardly used by different construction entities, which resulted in a divergent state of smartness. The scope and depth level of smart features in projects are varied and incomparable to similar projects. To some extent, this state is due to the exponential growth of technological developments. However, the lack of a commonly accepted framework or standards hinders a comprehensive understanding of the smart building concept. The first step toward an organized status is to provide relevant information and correct the perception about the smart building area. Construction students, as the future professionals involved in this area, are among those whose perceptions should 
be correctly and adequately shaped. Construction program can familiarize their students with different techniques, tools, methods, and equipment in the smart building area through courses, workshops, activities, and field trips. This study aimed to evaluate the perception of smart buildings in construction students from two different programs before and after a smart building workshop. A pre- and postworkshop survey was designed to quantify the data, and different statistical tests were used to analyze the data. Various comparisons showed similarities and differences in perception of students in both groups before and after the workshop.

\section{Smart Buildings}

Smart buildings are digitally connected structures that optimize "building and operational automation with intelligent space management to enhance the user experience, increase productivity, reduce costs, and mitigate physical and cybersecurity risks" (Wellner et al., 2018, p. 1). Smart Buildings are defined as "buildings which integrate and account for intelligence, enterprise, control, and materials and construction as an entire building system, with adaptability, not reactivity, at its core, in order to meet the drivers for building progression: energy and efficiency, longevity, and comfort and satisfaction." (Buckman et al., 2014, p. 104). Many smart buildings employ three distinct factors: improved intelligent features, controlling parameters, and internet of things (IoT) infrastructure (Verma et al., 2019). An integrated combination of these makes the operating system handle heating, ventilation and air conditioning, lighting, power systems, elevators, and fire alarms. IoT includes cameras, motion sensors, other surveillance systems, internal communication, and more. Additionally, I.T. systems, which include laptops, servers, and workstations, support other systems in an integrated smart network. Connections with technology partners may be helpful to owners, contractors, and managers to help plan and implement new building systems. To build a successful smart building, early collaboration between the owner, design team, and construction team is necessary (Sinopoli, 2010). Intel created its first IoTenabled smart building in 2016 in Bangalore, India. The office building was ten stories, 630,000 square feet, and consisted of 9,000 sensors to track and optimize temperature, lighting, energy usage, and building occupancy. Intel was challenged to reduce resource usage, improve operational efficiency, and increase occupant comfort. They did so with advanced building analytics, space optimization, and a machine learning algorithm. This building saved energy and water, increased employee capacity by approximately $30 \%$, and increased working satisfaction by $83 \%$ (Khandavilli, 2017). The Deloitte smart building framework emphasizes three D's: data, digital, and design. It "consists of the physical assets within the building, the digital assets that create a fabric throughout the connected space, and finally, the use cases that are enabled by the marriage of physical and digital assets" (Wellner et al., 2018, p. 2). The framework can connect people, supporting collaboration, optimizing control, and conserving resources.

Sub-segments of smart buildings include space-as-a-service, IoT, artificial intelligence/machine learning, workflow, augmented reality / virtual reality, and prefabricated construction. Navitas predicts a period of development with trial and error in a fashion similar to the internet's natural evolution (Navitas Capital, 2018). With these technologies, buildings offer new amenities, more efficient operations, cost savings, better environmental performance, and faster innovations(Principal Global, 2020). Traditional business models related to building operations and maintenance are becoming outmoded due to the rise in the smart building market. New technology, platforms, competitors, and customer preference have transformed the market. The three main market segments include energy efficiency, building automation, and connected homes. The building material market, unlike the three main market segments, has not experienced much change (Pieper et al., 2018). 
The four pillars of a smart building strategy are creating a better customer experience, enhancing energy efficiency, making operational improvements, and establishing a more sustainable environment. Generally, smart buildings emphasize multidisciplinary efforts to furnish an optimum combination of structural, utility, and managerial systems, which will result in cost efficiency and environment-oriented products (Wong et al., 2005). Although smart buildings have a higher initial construction cost, the benefit-cost ratio for smart buildings is higher than a conventional building, 1.99 to 0.88 , respectively, as reported. Cost savings are produced from lower operational and maintenance costs (Berawi et al., 2017). A building's energy efficiency can be improved by $10 \%$, yielding $\$ 0.30$ per square foot in annual savings using smart building technology. With smart sensors gathering occupancy data, space occupancy can be increased by $5 \%$, which typically amounts to $\$ 1.50$ per square foot in annual operating cost savings. Improving environmental comfort with smart building technology improves productivity by $2 \%$, yielding an annual cost savings of $\$ 6.00$ per square foot and a $10-25 \%$ reduction in absenteeism. This data translates to a $10-40 \%$ increase in operational hours, increased employee satisfaction by $24-40 \%$, reduced space per person while being more comfortable, and $30-40 \%$ reduction in real estate costs (Best, 2016).

Energy efficiency programs could aid the increased use of smart buildings, especially comprehensive programs versus single-system or single-measure retrofits. Introducing monetary incentives into these programs can promote smart building techniques further as well as help pay for hardware and thirdparty software companies to monitor building performance and suggest improvements. Educational facilities are now eligible for an ENERGY STAR grant but are often discouraged by the hefty costs in transitioning to green practices. Although the initial costs are high, they are a temporary hurdle for the long-term savings over the building's life. Smart building solutions can reduce energy consumption in educational buildings by ensuring computers and other appliances are not left running overnight while not in use (Entouch, 2020). "The potential of smart commercial buildings is enormous, generating energy and cost savings, upgrading control of building processes, promoting occupant comfort and convenience, and enhancing building value" (King \& Perry, 2017, p. 35).

\section{Smart Buildings in Construction Education Programs}

The construction industry is one of the largest segments of business in many countries. The industry is frequently reported to suffer from a lack of skilled workers. Universities and colleges can fill this gap by providing quality education for construction management students through workshops, internships, and curricular courses (Karji et al., 2020). Despite the fact, building-related programs fall short of providing new but required subjects such as smart building. Jolly et al. (2011) discussed the necessity of embracing smart building as a new concept in engineering education curriculum. In recent years a few construction programs have begun to offer courses on the smart building subjects such as Pennsylvania State University (Smart Buildings Operations Training course), Roxbury Community College (Building Operator Training program), Pittsburgh Technical College (Smart Building Technology program), and the University of San Francisco (Energy Systems Management program). While the smart building attracting the attention of professionals in the design and construction industry, it is not widely studied in construction education programs. Construction educational programs can be improved by delivering graduates with high-quality smart building knowledge to the industry.

\section{Methodology}

Smart building is a relatively new term in the design and construction industry and is increasingly discussed in related areas. Construction programs have begun different initiatives to embrace the 
subject. New construction courses are developed and offered, and research projects are defined to explore different aspects of smart buildings. The main purpose of this study was to explore the general understanding of construction students about smart buildings. This study was a part of a joint program between Mississippi State University in the U.S. and Nihon University in Japan. The joint program was established in 2017 to develop a collaborative effort in research and teaching through which faculty and students from each school could travel to the other country and participate in research and learning activities. The current study was defined as a tool to assess the general knowledge of the smart building concept among students who participated in a smart building workshop (Figure 1).
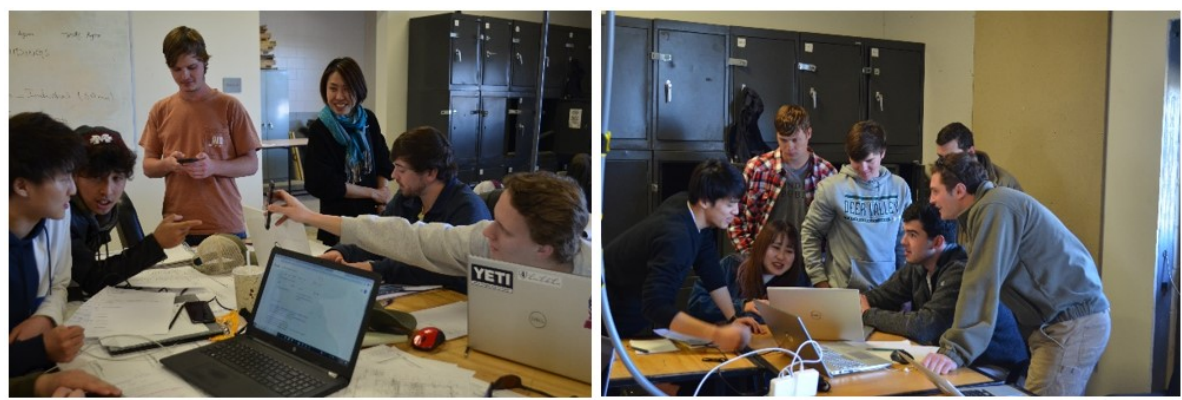

Figure 1. U.S. and Japanese Students collaboration in the smart building workshop

The workshop was a one-day event at Mississippi State University, U.S. In May 2019, faculty from both schools presented introductory topics on smart buildings. The introductory presentations were followed by a charrette in which students in mixed groups investigated one aspect or area related to smart buildings, collaborated in brainstorming sessions to develop new ideas, and presented them to the joint class. Based on the topics introduced by workshop faculty, a series of questions were created and included in a survey. Most questions used a five-level Likert scale to quantify students' level of perception or familiarity with smart buildings' different aspects. The same survey was administered at the beginning and then at the end of the workshop to provide pre-and post-data. Students in both groups were mostly in the second year of their programs and had not taken any specific smart buildings course. The survey questions did not require any specific technical knowledge to respond. The data from preand post-situations were collected, compiled, and organized to perform quantitative analysis. Descriptive statistical methods were used to perform frequency analysis. After the reliability test, Cronbach's alpha of .86 and .77 was obtained from the overall analysis of the pre- and post-workshop data, which categorizes the instrument's internal consistency as adequate (Taber, 2018). Results of the reliability analysis indicated that the items in the survey have an acceptable internal consistency.

\section{Data Collection and Discussion}

Following the methodology, the questionnaire survey was distributed between the workshop participants before and after the workshop. In total, 43 responses were collected, of which 8 were students from Nihon University in Japan, and 35 were students from Mississippi State University in the U.S. The following presents the important results of the survey.

\section{Smart Buildings' Barriers and Benefits}

Students were asked to express their opinion on the importance of the following smart buildings barriers using 5-point Likert scale questions for each item:

a1. Maintenance issues \& systems break-downs 
a2. Cost of installation and maintenance

a3. Cultural resistance to new technologies

a4. Integration/interoperability of different systems

a5. Learning how to operate new systems or training staff

a6. Lack of available suppliers/subcontractors/specialists

a7. Taking the responsibility of each technology by teams

The mean value of the Japanese group and U.S. group before and after the workshop was calculated.

Then the importance index of each barrier was calculated using the following equation:

Importance Index for barrier $\mathrm{x}=\frac{\text { Pre workshop mean value }+ \text { Post workshop mean value }}{2}$

Then, all the barriers were ranked based on their importance [Figure 2].

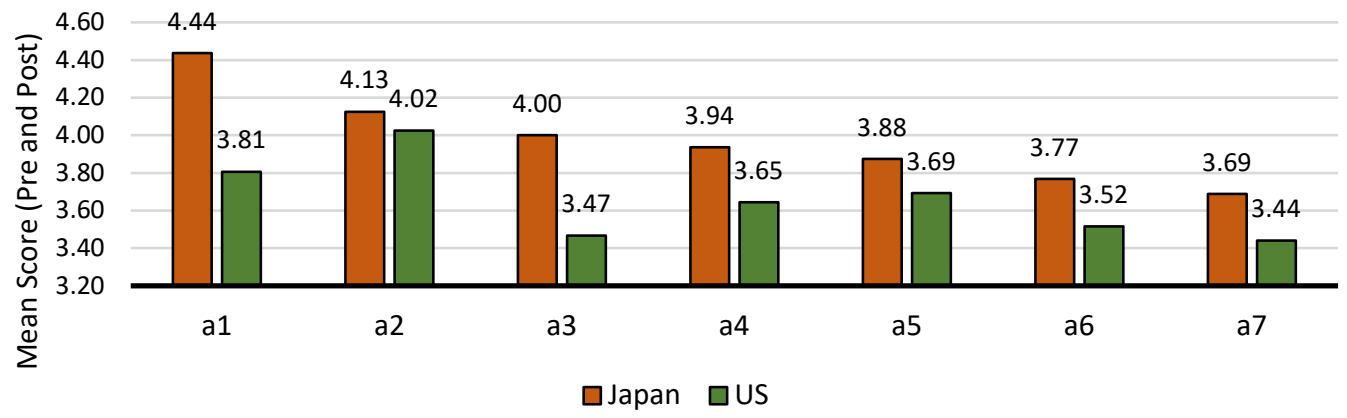

Figure 2. Smart buildings barriers ranked based on their importance index

Because of the 5-point Likert scale, the average mean score is 3 . This means that the respondents all agreed with the barriers. Based on the importance index, the "Maintenance issues \& systems breakdowns" and the "Cost of installation and maintenance" were perceived to be the most important barriers by the Japanese and U.S. groups, respectively. Figure 2 shows that, in general, the Japanese expressed more agreement with the questionnaire smart building barriers than the U.S. group. Japan is among the pioneer countries for smart building engagement (Becker et al., 2012). The difference between the students' perceptions of the barriers is important to note. A Wilcoxon signed-rank test was used to find out if the median differences are significant. This test is a non-parametric alternative to the t-test. The null hypothesis was that the median difference between Japan and the U.S. pairs for the barriers would be zero. The alternative hypothesis was that the median difference between pairs would not be zero. A significance level of 0.05 was used to examine seven pairs of data. The test results confirmed the alternative hypothesis, meaning that there is a difference between the opinions of the U.S. and the Japanese groups. However, further study is needed to investigate this pattern and to what degree the education systems in both countries have resulted in this pattern.

Similarly, students were asked to express their opinion on the degree to which they agree with the following smart buildings benefits using 5-point Likert scale questions for each item:

b1. Integration with other existing technologies (e.g., Google)

b2. Easier life

b3. Creating a more comfortable environment

b4. Improving security

b5. Cutting energy usage/costs 
b6. Cutting costs generally

b7. Reducing cost of changing occupancy and configuration

The mean value of each benefit's importance was calculated both for the pre-workshop and postworkshop survey. Then the importance index of each barrier was calculated using the following equation:

Importance Index for benefit $\mathrm{x}=\frac{\text { Pre workshop mean value }+ \text { Post workshop mean value }}{2}$

Then, all the benefits were ranked based on the importance of their benefits [Figure 3].

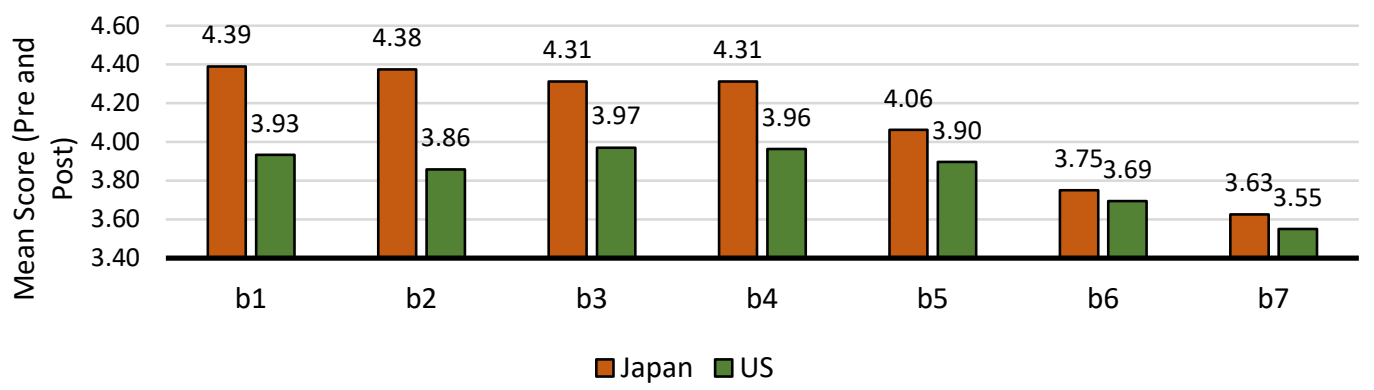

Figure 3. Smart buildings benefits ranked based on their importance

This graph shows that the smart buildings' most beneficial impact is perceived as the "Integration with other existing technologies" by the Japanese group and "Creating a more comfortable environment for customers" by the U.S. group. Because the importance index for all the benefits is above 3 , the respondents agreed with all the questionnaire benefits. Furthermore, the Japanese group rated all the benefits higher than the U.S. group. Similar to the barriers, another Wilcoxon signed-rank test was conducted, which resulted in a significant difference between Japan and the U.S. groups' opinions on smart buildings' benefits. Further investigation is also needed to study this pattern. But exploring the Japanese construction institution teaching method by the U.S. universities might be a good starting point. These students are the future experts in the construction industry and improving their opinions on smart buildings' benefits will pay off in the future by being more willing to build smart buildings.

\section{General Attitude and Familiarity of Smart Buildings}

This section presents the attitude and familiarity of the respondents on the smart building matter. In general, students had a good attitude towards smart building concepts. This was shown on the result of the following questions [Table 1].

Table 1. Familiarity of participants with smart building subject

\begin{tabular}{|c|c|c|c|}
\hline Question/Statement & $\begin{array}{c}\text { Overall Mean } \\
\text { Score }\end{array}$ & $\begin{array}{c}\text { Japan Mean } \\
\text { Score }\end{array}$ & $\begin{array}{c}\text { U.S. Mean } \\
\text { Score }\end{array}$ \\
\hline $\begin{array}{l}\text { Discussing Smart buildings are too soon for the } \\
\text { construction industry }\end{array}$ & 3 & $\begin{array}{l}\text { Pre: } 3.29 \\
\text { Post: } 3.50\end{array}$ & $\begin{array}{l}\text { Pre: } 2.49 \\
\text { Post: } 2.58\end{array}$ \\
\hline The belief that smart buildings save time & 3.75 & $\begin{array}{l}\text { Pre: } 4.13 \\
\text { Post: } 4.13\end{array}$ & $\begin{array}{l}\text { Pre: } 3.26 \\
\text { Post: } 3.85\end{array}$ \\
\hline All buildings eventually will become smart & 3.5 & $\begin{array}{l}\text { Pre: } 3.25 \\
\text { Post: } 3.88\end{array}$ & $\begin{array}{l}\text { Pre: } 3.25 \\
\text { Post: } 3.64\end{array}$ \\
\hline To what extent would you like to live in a smart building? & 3.7 & $\begin{array}{l}\text { Pre: } 4.00 \\
\text { Post: } 4.13\end{array}$ & $\begin{array}{l}\text { Pre: } 2.94 \\
\text { Post: } 3.63\end{array}$ \\
\hline
\end{tabular}


The respondents were also asked about their familiarity with smart buildings [Figure 4]

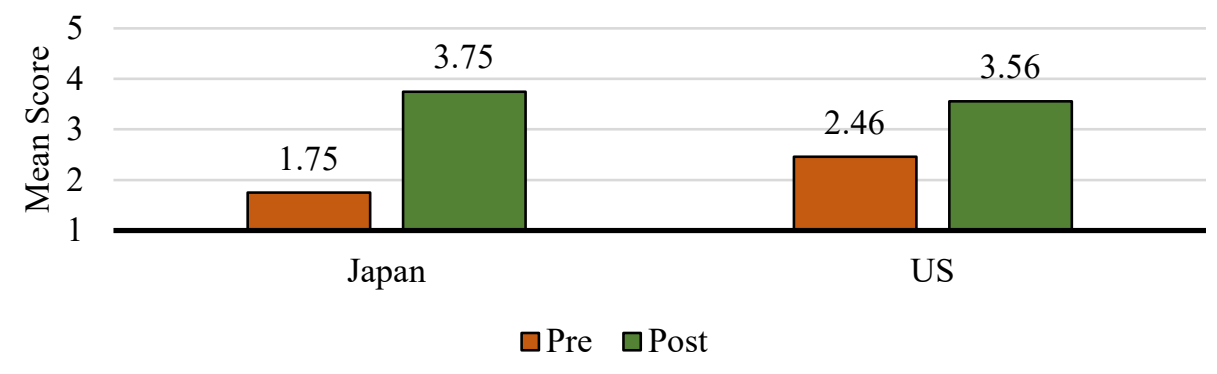

Figure 4. Familiarity with smart buildings in the Japanese and U.S groups

Based on this question's result, the smart building workshop was effective for both U.S. and Japanese groups [Figure 4]. Furthermore, the difference between before and after the workshop is higher in the Japanese group compared to the U.S. group. This means that the Japanese group gained more familiarity with smart buildings from the workshop. The pre-knowledge of both groups from the smart buildings is lower than 3, suggesting the need to increase awareness of smart buildings concepts. One reason for the students' low familiarity with the smart building concept could be due to not ever having a physical presence in a smart building. This was shown in one of the survey question's results. In this question, the students were asked if they had been in smart buildings. The results showed a mean score below 3 , suggesting that both the Japanese and U.S. groups had not experienced a visit to a smart building. This shows the importance of real-life experiences in promoting the smart buildings concept. Construction teachers can solve this problem by taking students on smart building tours.

\section{Role of Construction Education Institute to promote Smart Buildings Concept}

The survey participants were also asked about their confidence in learning and discussing smart building concepts [Figure 5].

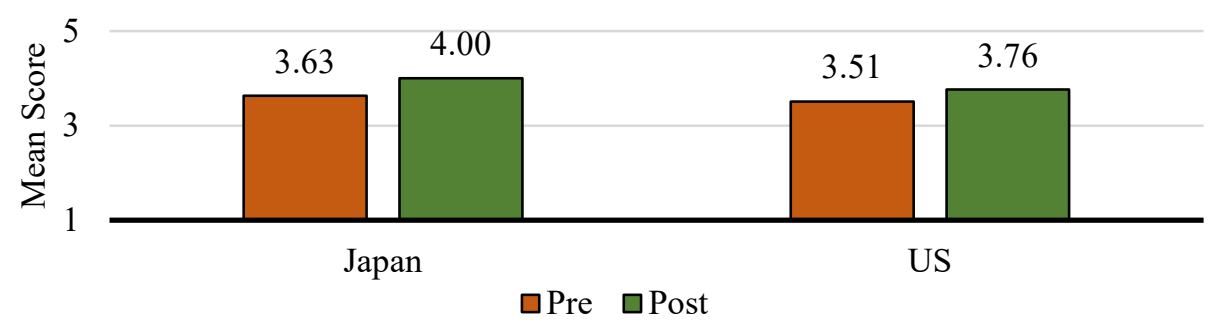

Figure 5. Confidence in construction education to learn smart buildings

This graph shows both the study group participants recognized academia's role in promoting the smart building concept. Furthermore, the workshop solidifies their opinion on this matter. This graph's important conclusion is the students' trust in construction education institutes to learn smart building concepts. It also highlights institutes' roles in improving students or future experts on smart building concepts. The respondents' answers indicated a higher mean score after the workshop for all the questions, and for both Japan and the U.S. This shows that a workshop can be very beneficial to boost students' perceptions of smart buildings. 


\section{Conclusion}

The market for smart building technology is increasingly expanding. More and more construction developers and homeowners find the benefits of adding energy-efficient, security components, and sustainable systems to their structures. While the smart building concept has changed to an underscore subject in the design and construction industry, it is not widely known in construction education programs. Knowing the current perceptions of construction students shows how the smart building scope and its elements may be effectively promoted. This study started with the objective of understanding the status of smart buildings on the students' knowledge. For this purpose, a study was designed and conducted in which two groups of construction-related students from Japan and the U.S. were surveyed. A quantitative research method was used to collect data. The study results were divided into three parts, including 1) barriers and benefits of smart buildings, 2) general attitude and familiarity of smart buildings, and 3) role of construction educational institute to promote smart building concept. Based on the results of the survey, the "Maintenance issues \& systems break-downs" and the "Cost of installation and maintenance" were perceived to be the most important barriers by the Japanese and U.S. groups, respectively. In general, the Japanese expressed more agreement with the questionnaire smart building barriers compared to the U.S. group. The result of the Wilcoxon test showed that this difference is significant. Regarding the benefits of smart buildings, the most beneficial impact is perceived as the "Integration with other existing technologies" by the Japanese group and "Creating a more comfortable environment for customers" by the U.S. group. To compare the groups, a Wilcoxon signed-rank test was utilized, which confirmed the difference between the U.S. and the Japanese groups' opinions. In general, students had a good attitude towards smart building concepts [Table 1]. However, the pre-knowledge of both groups of smart buildings is lower than 3, suggesting the need to increase awareness of smart buildings' concepts. As pointed out in the survey, both the Japanese and U.S. group lack the real-life experience of visiting actual smart buildings, which could be the reason for their low familiarity. Construction educators can solve this problem by taking students on smart building tours. Finally, the survey focused on the role of construction educational institutions in promoting smart building knowledge. The results showed that both study group participants recognized academia's role in promoting the smart building concept. Furthermore, the workshop solidifies their opinions on this matter. This highlights the institutes' role in improving students and future experts on the smart building concept. The respondents' answers indicated a higher mean score after the workshop for all the questions, and for both Japan and the U.S. This shows that a workshop in a class (e.g., Sustainability, Mechanical and Electrical, or Capstone) be very beneficial to boost students' perceptions of smart buildings. One of the main limitations of this study was the low number of participants from the Japanese institute compare to the U.S. students' group. Although the study has limitations, the results are expected to shed light on smart building education for the construction institute.

\section{References}

Becker, B., Kellerer, A., \& Schmeck, H. (2012). User interaction interface for Energy Management in Smart Homes. 2012 IEEE PES Innovative Smart Grid Technologies (ISGT), 1-8. https://doi.org/10.1109/ISGT.2012.6175616

Berawi, M. A., Miraj, P., Sayuti, M. S., \& Berawi, A. R. B. (2017). Improving building performance using smart building concept: Benefit cost ratio comparison. AIP Conference Proceedings, 1903(1), 030001. https://doi.org/10.1063/1.5011508

Best, B. (2016, April 20). Smart Buildings: The Workplace of Tomorrow, Today. Work Design Magazine. https://www.workdesign.com/2016/04/smart-buildings-the-workplace-of-tomorrowtoday/). 
Buckman, A. H., Mayfield, M., \& Beck, S. (2014). What is a Smart Building? Smart and Sustainable Built Environment, 3(2), 92-109. https://doi.org/10.1108/SASBE-01-2014-0003

Entouch. (2020). Smart Building 101 for Education Facilities: Efficient Energy Management For A Better, Brighter, Tomorrow. https://cdn2.hubspot.net/hubfs/2483721/Smart\%20Building\%20101\%20for\%20Education\%20\%20EDU_VP050917.pdf

Jolly, A.-M., Léger, C., \& Lamarque, G. (2011). "Smart building":anewconceptofengineering education curriculum. WorldEngineers'Convention, Geneva,Switzerland. https://hal.archivesouvertes.fr/hal-00607817

Karji, A., Bernstein, S., Tafazzoli, M., Taghinezhad, A., \& Mohammadi, A. (2020). Evaluation of an Interview-Based Internship Class in the Construction Management Curriculum: A Case Study of the University of Nebraska-Lincoln. Education Sciences, 10(4), 109. https://doi.org/10.3390/educsci10040109

Khandavilli, S. (2017). Intel Creates Smart Building Using IoT. https:/www.intel.com/content/www/us/en/smart-buildings/smart-building-using-iot-casestudy.html

King, J., \& Perry, C. (2017). Smart Buildings: Using Smart Technology to Save Energy in Existing Buildings | ACEEE. https://www.aceee.org/research-report/a1701

Navitas Capital. (2018). Smart Buildings. https://navitascap.com/wpcontent/uploads/2018/08/NAVITAS-CAPITAL-SMART-BUILDINGS-WHITE-PAPER-1.pdf

Pieper, C., Maciel, J., de Laubier, R., Wunder, M., \& Metzdorf, A. (2018). A Guide to the Revolution in Smart Buildings. https://www.bcg.com/publications/2018/guide-revolution-smart-buildings

Principal Global. (2020). Smart building strategy. https://www.principalglobal.com/documentdownload/45725

Sinopoli, J. (2010). Smart building systems for architects, owners, and builders. Elsevier/ButterworthHeinemann.

Taber, K. S. (2018). The use of Cronbach's alpha when developing and reporting research instruments in science education. Research in Science Education, 48(6), 1273-1296.

Verma, A., Prakash, S., Srivastava, V., Kumar, A., \& Mukhopadhyay, S. C. (2019). Sensing, Controlling, and IoT Infrastructure in Smart Building: A Review. IEEE Sensors Journal, 19(20), 9036-9046. https://doi.org/10.1109/JSEN.2019.2922409

Wellner, P., Michalik, J., Manolian, H. A., \& James, G. (2018a). Smart Buildings: Four considerations for creating people-centered smart, digital workplaces. https:/www2.deloitte.com/content/dam/insights/us/articles/4748_Smart-buildings/DI_Smartbuildings.pdf

Wong, J. K. W., Li, H., \& Wang, S. W. (2005). Intelligent building research: A review. Automation in Construction, 14(1), 143-159. https://doi.org/10.1016/j.autcon.2004.06.001 